\title{
ALGUNAS REFLEXIONES EN TORNO AL DERECHO AL AGUA, EN ESPECIAL SOBRE SU RECEPCIÓN Y EJECUTABILIDAD EN EL ORDENAMIENTO JURÍDICO CHILENO
}

\author{
Fernando Ochoa Tobar* \\ Universidad de Concepción, Chile \\ fernando.ochoa.udec@gmail.com
}

RESUMEN: El presente trabajo se ocupa, en primer término, de la génesis y contenido del Derecho al Agua, para luego reflexionar en torno a su recepción en el Ordenamiento Jurídico Chileno y sus reales posibilidades de ejercicio a través de las acciones y recursos consagrados en él para la defensa de los derechos humanos. Finalmente, medita en torno a los conflictos que pueden surgir entre la legislación de aguas y los principios que lo inspiran.

Palabras clave: derechos humanos, derechos sociales, agua, saneamiento.

\begin{abstract}
This work deals first upon the creation and content of the Right to Water, to arrogate then reflect upon their arrival at the Chilean legal system and their real possibilities of exercising through the actions and resources to defend the human rights. Finally meditates about the conflicts that can take place between the chilean water legislation and the principles behind the content of this Right.
\end{abstract}

Keywords: human rights, social rights, water, sanitation.

* Egresado de la carrera de Derecho, Universidad de Concepción, Chile. Ayudante del Departamento de Historia y Filosofía del Derecho, periodo 2009, y ayudante del Departamento de Derecho Público, periodo 2010, en la carrera de Derecho de dicha Universidad. Correo electrónico de contacto: fernando.ochoa.udec@gmail.com. Quisiera agradecer la gran ayuda de Esteban Neira, ayudante del Departamento de Historia y Filosofía del Derecho, en la síntesis de este trabajo, no siendo responsable de las opiniones contenidas en él. 


\section{EL DERECHO HUMANO AL AGUA. BREVES NOTAS SOBRE SU GÉNESIS}

Si bien la necesidad de agua para mantener la vida es indiscutible, el desarrollo del hombre, sus actividades y sus asentamientos le han impuesto a esta necesidad nuevas particularidades, que tornan su satisfacción más compleja, pues el agua no cumple única y exclusivamente esta función. Desde luego, estas particularidades, intereses y utilidades pueden conducir a priorizar algunos usos en perjuicio de otros, o bien lograr un compromiso que permita un desarrollo armónico. Pero, debe tenerse presente que esta creciente utilidad va acompańada por una creciente escasez del recurso.

Lo expresado tiene también un planteamiento para el Derecho. Así, buscando dar una armoniosa solución a estas complejas necesidades, y con un intenso contenido moral en sus cimientos, surge un movimiento que mediante diversos instrumentos y normas busca el reconocimiento del Derecho al Agua como un Derecho Fundamental.

Es en el plano del Derecho Internacional de los Derechos Humanos donde comienza a tomar forma esta idea, complementando el acceso al agua con otros caracteres en aras de proporcionar condiciones de vida digna a todas las personas de todos los pueblos. Así, se cita la Conferencia de las Naciones Unidas sobre el Agua llevada a cabo en Mar del Plata en 1977, o la Declaración de Dublín de 1992, sobre todo por su referencia a ser un "derecho fundamental" 1 . Dentro de los instrumentos relativos a derechos humanos con vocación universal, se distinguen aquellos que lo recogen "como asunciones implícitas de la existencia de este derecho, integrante de otros como el derecho a la alimentación, la vivienda, etcétera; o con carácter autónomo dentro del marco general del derecho a un nivel de vida adecuado o a través de menciones muy genéricas a su reconocimiento, sin precisión de detalle, que tienen como destinatario a colectivos específicos (mujeres y niños) y no a la totalidad de los seres humanos, y de nuevo con respecto a ciertos derechos humanos concretos (alimentación e higiene de los niños) o en espacios sociales determinados (el medio rural para la mujer)"2.

Algunos, por tratarse de declaraciones, no se tradujeron en obligaciones jurídicas efectivas, pero aportaron indirectamente, constatando una revolución silenciosa, o introduciendo bases que después servirían para la construcción jurídica definitiva del derecho.

Ni el Pacto Internacional de Derechos Civiles y Politicos, ni el Pacto Internacional de Derechos Económicos, Sociales y Culturales, hacen mención alguna sobre él. Pero debe tenerse presente el artículo 11 párrafo I de este último, que consagra el derecho a un nivel de vida adecuado, y que permite, en aras de la progresividad, plantear nuevas manifestaciones de él.

Smets, Henri. Por un derecho efectivo al agua potable. Bogotá, Colombia: Editorial Universidad del Rosario, 2006, p. 19.

2 SÁnchez, Víctor M. "Hacia un derecho humano fundamental al agua en el derecho internacional”, en Revista Electrónica de Estudios Internacionales. <En línea>, Asociación Española de Profesores de Derecho internacional y Relaciones internacionales, Madrid, España, Nº 16, 2008. [Citado 29 Junio 2010] Disponible en la World Wide Web: <http://www.reei. org/reei\%2016/doc/SANCHEZ_Victora.pdf> 
Y sobre la base del Pacto, debe acudirse al Comité y a sus Observaciones Generales. Pues encontramos alusiones al Derecho al Agua ya en las Observaciones Generales $\mathrm{n}^{\circ} 4$ (Derecho a la vivienda), n 6 (Derechos Económicos, Sociales y Culturales de las personas mayores de edad), $\mathrm{n}^{\circ} 13$ (Derecho a la Educación), $\mathrm{n}^{\circ} 14$ (disfrute del más alto nivel de salud posible). Pero es con la Observación General n 15 del año 2002 con la cual se da el paso definitivo y esencial. Intitulada Derecho al Agua, que en su introducción señala que el agua es un recurso natural limitado y un bien público fundamental para la vida y la salud.

Podemos sintetizar sus caracteres fundamentales en, primero, su intrínseca unión con la dignidad humana y su carácter indispensable para una vida digna. Segundo, su condición de presupuesto para la realización de otros derechos fundamentales. Tercero, la obligación que pesa sobre los Estados de adoptar medidas para hacer efectivo este derecho, sin discriminación alguna. Y finalmente, el agua es esencialmente un bien social y cultural, no solo económico.

\section{EL DERECHO HUMANO AL AGUA; PLANTEAMIENTO INTERNACIONAL}

\subsection{El Derecho Humano al Agua; Concepto}

Ha sido definido como el derecho de todos a disponer de agua suficiente, salubre, aceptable, accesible y asequible para el uso personal y doméstico. De este concepto, se desprende su carácter primario y básico. Empero, hay quienes son de la opinión de que en razón de este concepto, debería hablarse de "derecho al agua potable y al saneamiento"3.

El Comité, en la Observación General n 15 , declara a este derecho como Humano y, como tal, además de indispensable para una vida digna, es presupuesto de otros derechos humanos. Este derecho se enmarcaría dentro de los arts. 11 y 12 del Pacto y, así, el Comité considera que el Derecho al Agua está indisolublemente unido al nivel más alto de salud posible, al derecho a la vivienda y a la alimentación adecuada; al derecho a la vida y a la dignidad humana y al derecho al trabajo y a participar en la vida cultural.

Lo anterior, por cuando en opinión del Comité estaría incluido en el art. 11 del párrafo I, dentro del derecho a un nivel de vida adecuado, pues el uso de la palabra 'incluso' indica que la enumeración que en él se hace no es exhaustiva.

3 Saura Estapà, Jaume. "Agua y derechos humanos: las bases del derecho humano al agua”, en Serie Carta de Derechos Humanos Emergentes: Derecho Humano al acceso al agua potable y al saneamiento. < En Línea $>$ Institut de Drets Humans de Catalunya, Cataluña, España, No 4, 2008, p. 123. [Citado 29 junio 2010]. Disponible en la World Wide Web: <http://www.idhc.org/esp/documents/Biblio/CDHE_04.pdf> 
Como Derecho Económico, Social y Cultural es de aquellos que "explicitan las exigencias de los valores de dignidad, igualdad y de solidaridad humana, buscando superar las desigualdades sociales, generando el derecho de participar en los beneficios de la vida social o, al menos, a un mínimo vital compatible con la dignidad humana a través de derechos y prestaciones brindadas directa o indirectamente por los poderes públicos" ${ }^{4}$. Y "se trata de un derecho de prestación ya que consiste en exigir una prestación a los poderes públicos de suministrar agua potable y de sanear las aguas residuales" 5 . Así, según la Observación no 15, es el Estado quien debe intervenir ejecutando estas prestaciones y eliminando injerencias en su ejercicio. Ello importa al analizar sus violaciones, pues genéricamente se manifiestan "en lagunas de disposiciones y/o carencias en las prestaciones que reclamarian medidas coercitivas no siempre accionables" 6 .

Mas, si se considera el acceso al agua como indispensable para la vida, podríamos ubicarlo como un derecho de primera generación "por ser anterior a la formación del mismo Estado, y por tratarse de un derecho intrinseco a la naturaleza humana, y la función gubernamental deviene únicamente en reconocerlo y regularlo. Por su parte, el derecho a la acción pública en protección del agua es posterior al establecimiento del Estado y, por tanto, se ejerce frente a este, necesita su plena intervención para su debida implementación y protección, visto de esta perspectiva compartiría características con los derechos económicos, sociales y culturales, y con los derechos de la solidaridad"7.

Entonces, si el derecho al agua se encontraba reconocido con anterioridad al pronunciamiento de la Observación, podemos concluir que el gran avance de esta radica en conceptuar el mismo y definir su contenido. Y al definir un contenido propio se permite concebirlo como diferente y autónomo de otros con los cuales ha estado vinculado.

\subsection{El CONTENido DEL DERECHO}

Su contenido normativo entraña tanto libertades como derechos. Primero, las libertades consisten en el derecho a mantener el acceso a un suministro de agua necesario para ejercer

4 Nogueira Alcalá, Humberto. "Los derechos económicos, sociales y culturales como derechos fundamentales efectivos en el constitucionalismo democrático latinoamericano”, en: Estudios constitucionales, vol. 7, n 2, p. 152. Talca, Chile: Centro de Estudios Constitucionales, Universidad de Talca, 2009.

5 Peñalver Cabré, Alex. "Aproximación al marco jurídico del derecho humano al agua: una perspectiva desde el derecho interno", en Serie Carta de Derechos Humanos Emergentes: Derecho Humano al acceso al agua potable y al saneamiento. <En Línea> Institut de Drets Humans de Catalunya, Cataluña, España, No 4, 2008, pp. 8 y ss. [Citado 29 junio 2010]. Disponible en la World Wide Web: <http://www.idhc.org/esp/documents/Biblio/CDHE_04.pdf>

6 Ferrajoli, Luigi. Derechos y garantías; La ley del más débil. -4a edición-Madrid, España: Editorial Trotta, 2004, p. 109.

7 Peña Chacón, Mario. "Derecho Humano al Agua”, en Medio Ambiente \& Derecho: Revista electrónica de derecho ambiental. <En Línea> Grupo de Investigación de Medio Ambiente y Derecho, Universidad de Sevilla, España, No 16, septiembre 2007 [Citado 29 junio 2010]. Disponible en la World Wide Web: <http://huespedes.cica.es/aliens/ gimadus/16/08_dere_human_agua.htm> 
el derecho al agua y el derecho a no ser objeto de injerencias. Constituyen ejemplos de estas injerencias los cortes arbitrarios del suministro o la contaminación de los recursos hidricos. Ello cobra importancia en los países que han adoptado sistemas en que la provisión del agua está entregada a particulares. Así, la Observación prescribe que antes de que un Estado Parte o un tercero haga algo que interfiera con el Derecho al Agua de una persona, se deberá velar porque tales medidas se ejecuten de un modo previsto por la legislación que sea compatible con el Pacto, incluyendo: a) la oportunidad de una auténtica consulta con los afectados; b) el suministro oportuno de información completa sobre las medidas proyectadas; c) la notificación con antelación razonable de las medidas proyectadas; d) la disponibilidad de vías de recurso y reparación para los afectados; y e) asistencia juridica para obtener una reparación legal. Cuando tales medidas se emprendan porque una persona adeuda el pago de agua, deberá tenerse en cuenta su capacidad de pago. No podrá privarse a una persona del mínimo indispensable de agua. La obligación de cubrir la necesidad no satisfecha y amparada por el orden interno, pasa a los propios Estados.

Segundo, los derechos comprenden el derecho a un sistema de abastecimiento y gestión del agua que ofrezca a la población iguales oportunidades de disfrutar del derecho. En este caso, los Estados pueden actuar subsidiariamente tutelando el respeto al derecho e igualdad en su ejercicio.

Pero, a su vez, los elementos del derecho deben ser adecuados a la dignidad, vida y salud humanas, en los términos del párrafo primero del art. $11 \mathrm{y}$ del art. 12 del pacto. Esto implica su mejora continua en concordancia con las condiciones de vida de las personas, traduciéndose en la revisión y control de los sistemas implementados y en su actualización.

El ejercicio del derecho no está exento de límites. Por una parte está la naturaleza misma del agua, en tanto bien social y cultural -caracteres antepuestos a su función económica- y el carácter sostenible de este ejercicio, resguardándolo también para las generaciones futuras. Pero el límite más interesante es el establecer mínimos invariables de condiciones adecuadas para su pleno ejercicio, que permiten su mejora y a su vez restringen la capacidad de los Estados para rebajarlas, estableciéndose criterios internacionales, cuya variación exigiría nuevos pactos, que encontrarían un freno en la prohibición de regresividad de los derechos humanos.

El primero de los factores que se aplica es la disponibilidad. El abastecimiento de agua de cada persona debe ser continuo y suficiente para los usos personales y domésticos. Segundo, en lo relativo a la calidad, el agua debe ser salubre y, por lo tanto, no ha de contener elementos que puedan constituir una amenaza para la salud de las personas. En lo tocante al factor accesibilidad, el agua y las instalaciones y servicios deben ser accesibles a todos, sin discriminación alguna. La accesibilidad presenta cuatro dimensiones superpuestas: una físi$c a$, pues el agua, las instalaciones y servicios de agua deben estar al alcance físico de todos 
los sectores de la población, no amenazándose la seguridad física al acceder a estas; una económica, en que los costos y cargos directos e indirectos asociados al abastecimiento de agua deben ser asequibles y no deben comprometer el ejercicio de otros derechos reconocidos en el Pacto; una referida a la no discriminación, pues el agua y los servicios e instalaciones de agua deben ser accesibles a todos, de hecho y de derecho, incluso a los sectores más vulnerables y marginados de la población, garantizando tarifas igualitarias, y como última está el acceso a la información.

\subsection{No discriminación, Igualdad y Derecho al Agua}

Como se sabe, los derechos humanos son universales. Pero esta universalidad se entronca, además, con la igualdad de todos los hombres en cualquier tiempo y lugar ${ }^{8}$. La igualdad viene a prevenir y corregir los defectos de una libertad ilimitada. Así, frente a la libertad que se concede, los titulares se presentan como iguales 9 . Pero como la igualdad puede ser germen de injusticias se admite la desigualdad en aras de bienes jurídicos superiores. Dotado este derecho de un contenido doble, libertad y derecho, se ejerce por todos en un pie de igualdad, igualdad que de ninguna manera es irrestricta. En efecto, si el derecho al agua es universal y por definición se reconoce a todos, es lógico que dentro del concepto de elementos adecuados se deba hacer consideraciones en orden a la igualdad. Deben sí tenerse en cuenta las discriminaciones de facto, pues la distribución inadecuada puede redundar en discriminación, cuando, aun existiendo los recursos, estos se enfocan, en los hechos, en algunos sectores.

Pero, como dijimos, aun la igualdad irrestricta puede redundar en privación o perturbación en el ejercicio del derecho si las condiciones determinan que unos necesitan más agua que otros, o requieren de una calidad diversa que la mayoría. Aquí, los correctivos resultan imperiosos. Ya antes de la Observación no 15 se dijo que aun en tiempos de grave escasez, se debe proteger a los miembros vulnerables adoptando programas específicos a un costo relativamente bajo. Y aun dentro de los grupos vulnerables, se exige una particular atención respecto de las mujeres, los niños, los grupos minoritarios, los pueblos indígenas, los refugiados, los solicitantes de asilo, los desplazados internos, los trabajadores migrantes, los presos y los detenidos.

8 Bidart Campos, Germán. Teoría general de los Derechos Humanos. D.F., México: Universidad Autónoma de México, 1989, p. 45.

9 Ibid., p. 193. 


\section{EL DERECHO HUMANO AL AGUA. SU RECEPCIÓN EN EL ORDENAMIENTO JURÍDICO CHILENO}

\subsection{LA RECEPCIÓN EN EL DERECHO INTERNO; UN PROBLEMA DE FONDO}

Pese a su progresivo reconocimiento y proclamación como parte del Derecho Internacional de los Derechos Humanos no se ha generado un impacto en el ordenamiento nacional como para reconocer expresamente el del derecho de todos a disponer de agua, aunque aun cabe preguntarse si los actuales textos positivos relativos a derechos humanos, son lo suficientemente amplios como para considerarlos un reconocimiento del Derecho al Agua, o facilitar su incorporación.

El principal catálogo de derechos y garantías, el art. 19 de la Constitución Política, no contiene referencia alguna al Agua como un Derecho Humano. Pero sí reconoce y protege la propiedad que sobre el derecho de aprovechamiento tiene su titular. Además, garantiza el derecho a la vida ( $\left.n^{\circ} 1\right)$, y también el derecho a la protección de la salud ( $\left.n^{\circ} 9\right)$. Consagra también el derecho a vivir en un medio ambiente libre de contaminación ( $n^{\circ} 8$ ). A su vez, están derechos como a la educación $\left(\mathrm{n}^{\circ} 10\right.$,) y a desarrollar cualquier actividad económica (no 21).

Pues bien, considerando este Derecho indisolublemente unido a otros derechos humanos -manifestación del carácter de interrelacionados que ostentan- existe una innegable vinculación entre el ejercicio del Derecho al Agua y todos estos derechos. Así, por ejemplo, la vida no puede ser concebida sin agua y, por lo tanto, el acceso a ella es un contenido fuera de toda discusión dentro de la garantía del no 1 del art. 19 de la Carta Magna.

Pero al hacerse depender esta interpretación de relaciones subentendidas y condicionadas a una necesidad imperiosa, cuya falta ponga en riesgo otros derechos sí consagrados, ¿puede de esta forma privársele de un contenido propio o darle un contenido incompleto y, en casos más graves, transformarlo en un derecho dependiente en sus aspectos funcionales? Otro problema puede presentarse en aquellas relaciones que no sean tan obvias. O, lo que es más grave, que una lectura circunscrita al numeral 24, termine por centrar su discusión no en el acceso como forma de satisfacer necesidades, sino como la reclamación de un derecho sobre una cosa, reduciéndolo a una cuestión de propiedad y turbación de la misma.

Sin embargo, la Constitución asegura estos derechos, no los crea, pues ellos emanan de la misma naturaleza humana y, por tanto, no se agotan en dicha enumeración. Y es así como es importante tener presente el art. 50 inciso 2 de la Constitución, según el cual, la soberanía reconoce como limitación el respeto de los derechos esenciales que emanan de la naturaleza humana y que es deber de los órganos del Estado respetar y promover tales derechos, garantizados por esta Constitución, asi como por los tratados internacionales ratificados por Chile y que se encuentran vigentes. 
Citando al profesor Nogueira Alcalá, "los derechos esenciales asegurados por tratados internacionales ratificados por Chile y vigentes son parte de los derechos que constituyen límites a la soberanía, en la medida que el propio Estado mediante la ratificación los ha considerado como tales, ya que normalmente los tratados que los contienen los definen como atributos esenciales de las personas o como derivaciones de la dignidad humana, como ocurre, entre otras convenciones y pactos (...) Con el Pacto Internacional de Derechos Económicos, Sociales y Culturales de Naciones Unidas" ${ }^{\prime \prime}$.

Entonces, basta con que un tratado internacional, ratificado y vigente, consagre el Derecho al Agua para que se produzcan estos efectos. Y, dentro de tales tratados, encontramos a la Convención sobre los Derechos del Niño en su art. 24; la Convención sobre la Eliminación de todas las Formas de Discriminación contra la Mujer en su art. 14, los Protocolos adicionales I y II a los Convenios de Ginebra de 1949, en sus arts. 54 y 4, respectivamente, encontrándose también referencias en la Convención de las Naciones Unidas sobre los derechos de las personas con discapacidad en su art. 28. Todo esto recordando la formulación general del derecho contenida en los arts. 11 y 12 del Pacto Internacional de Derecho Económicos, Sociales y Culturales del Derecho a un nivel de vida adecuado. Sin embargo, ¿es acaso aplicable lo anterior a la Observación $n^{\circ} 15$ ? Debe tenerse presente que ella no es un tratado, sino más bien una interpretación no vinculante. Sobre el particular, creemos que la adecuada lectura del texto constitucional es que el respeto es a los derechos que se contienen en los tratados, y esta responde a una interpretación de un derecho que sí está contenido en un tratado sobre Derechos Humanos bajo la fórmula amplia del art. 11 del Pacto. Y tan presente estaba, que se reconoce su indisoluble unión con otros. Se dirá que esa lectura del Comité solo busca facilitar la aplicación del pacto, no imponiendo normas específicas a los Estados. Pero podrá contra argumentarse que esta interpretación uniforma el criterio del Comité al evaluar los informes que deben presentar los Estados parte, y que, a la larga, se traduce en que su contenido sí es vinculante en el ordenamiento interno.

Mas lo expresado, cruzando nuestras fronteras, se vuelve mucho más difuso de lo que ya era. Así, el Código de Aguas declara que las aguas son bienes nacionales de uso público, pero les otorga a los particulares el derecho de aprovechamiento de ellas. Este es un derecho real y perpetuo que recae sobre las aguas y consiste en el uso y goce de ellas, concediéndose gratuitamente a quien los solicita cumpliendo con las condiciones legales. Pero este sistema se ha prestado para variados abusos e inequidades. Antes no existía la obligación de justificar la necesidad del caudal de agua solicitado, bastaba con pedirla y cumplir los requisitos legales. Con la reforma de la Ley 20.017 al Código de Aguas, se introdujo al art. 140 la alusión a la necesidad y la obligación de acompañar una memoria explicativa en que se señale la can-

10 Nogueira Alcalá, Humberto. "Aspectos de una Teoría de los Derechos Fundamentales: La Delimitación, Regulación, Garantías y Limitaciones de los Derechos Fundamentales", en: Ius et Praxis, vol. 11, no 2, p. 28. Talca, Chile: Facultad de Ciencias Jurídicas y Sociales, Universidad de Talca, 2005. 
tidad de agua que se necesita extraer según el uso que se le dará, pero solo cuando supera las cantidades a que el citado precepto hace referencia, y nada impide posteriormente destinar ese mismo caudal a un uso diferente al originalmente propuesto. Si se presentaran dos o más solicitudes respecto de un mismo cauce y no existiendo aguas suficientes para satisfacerlos a todos, mientras el Código del año 1951 establecía un orden de preferencias de los usos, que comenzaba con la bebida y servicio de agua potable de las poblaciones y centros industriales, el Código actual opta por un sistema de remates, que en la práctica permite pasar de un sistema de concesión gratuita del derecho a favor de quien lo solicite a uno en que se constituye a favor de quien pueda pagarlo -quien se lo adjudicó-, aun en perjuicio de quien realmente lo necesite. Aún más, el establecimiento de la obligación del pago de una patente, progresiva por el no uso de las aguas, no extingue en verdad los fines especulativos de aquel que tenga medios para soportar su carga.

\subsection{La justiciabilidad y exigibilidad del Derecho al Agua}

Primero, debe considerarse la posibilidad de exigibilidad del Derecho, pues estando su contenido estructurado como un conjunto de prestaciones del Estado, solo es eficaz si se consagran instrumentos para provocar su exigencia. Pues bien, en la legislación chilena encontramos algunas normas en leyes sectoriales, tendientes a la prestación de servicios sanitarios, pero sin un carácter general. Todavía podría acudirse a la norma constitucional que consagra el Derecho de Petición, sin embargo, queda el problema de la falta de competencia de los órganos estatales para actuar, lo que transforma en efímera esta vía.

Pero también deben considerarse recursos para lograr la protección de su ejercicio, para corregir los defectos en su satisfacción o, en un caso más extremo, para sancionar violaciones. Así, según la Observación, toda persona o grupo que haya sido víctima de una violación del derecho al agua deberá contar con recursos judiciales o de otro tipo efectivos tanto en el plano nacional como en el internacional, y además, las victimas de las violaciones del derecho al agua deben tener derecho a una reparación adecuada, estableciéndose en ella un breve catálogo de violaciones, no taxativo, consecuencia lógica del contenido del derecho y de las obligaciones de los Estados. Sin embargo, ¿son los derechos Económicos, Sociales y Culturales, o a lo menos es conveniente que sean, susceptibles de ser cautelados por los tribunales de justicia? Esto es relevante, pues la Observación no 15 enmarca el Derecho al Agua dentro del art. 11 del Pacto. ¿Podría un tribunal adentrarse en temas tan complejos como la calidad del agua potable? ¿Debería un tribunal por vía de un recurso o acción revisar todo el plan de recursos hídricos del gobierno y hacer modificaciones a su política? $\mathrm{O}$ ¿podría un tribunal decidir con la suficiente sabiduría cómo suministrar agua para ciertas actividades sin perjudicar o impedir otras? En todas estas hipótesis, el tribunal debe pronunciarse, aún más si se le prohíbe excusarse ante el requerimiento de las partes, no pudiendo ninguna de estas consideraciones inhibirlo. 
Mas la defensa del derecho en el plano interno no se agota en el solo orden judicial, sino en un sistema integral de defensa, que comprende recursos tendientes a provocar la actividad de otros poderes del Estado, como el Ejecutivo. Esto es importante, sobre todo por la forma en que en nuestro sistema ha sido consagrado el agotamiento de la vía administrativa.

¿Existen, entonces, dentro de nuestro ordenamiento jurídico instrumentos que logren, aunque sea indirectamente, incoar la acción de los órganos del Estado? El principal instrumento que contempla para la cautela de los derechos fundamentales, es la acción de protección consagrada en el art. 20 de la Carta Magna. Pero ella solo procede respecto de algunos de los derechos y garantías establecidos en su art. 19, entre los que no se encuentra el Derecho Humano al Agua, de manera que las posibilidades de salvaguardarlo quedan reducidas a determinar si la privación, perturbación o amenaza del ejercicio de alguno de los otros derechos o garantías que sí se encuentran contemplados en el art. 19, y con los cuales está indisolublemente unido, autoriza para recurrir de protección.

Por la vía de la protección es posible impugnar actos u omisiones arbitrarias que perturben o amenacen el goce del derecho de aprovechamiento. Pero en este caso se protege la propiedad sobre dicho derecho, y no se reivindican propiamente las aguas, pues no se es dueño de ellas, aunque el efecto es el mismo, pues el fin es restablecer la situación de hecho que consiste en el goce de las aguas sobre las cuales se constituyó la merced.

Sin embargo, respecto a los cortes del suministro de agua potable que no provienen de las prestadoras de servicios sanitarios, se ha resuelto que "mediante la voluntariosa acción (el corte de suministro), cuya realización reconoce el recurrido en su informe, se ha vulnerado el derecho de propiedad sobre un bien de carácter incorporal, como es el derecho a gozar de un suministro de agua potable que constituye un bien indispensable para la mantención de la vida...”.

En cuanto al numeral 21, los tribunales han resuelto que el corte ilegal o arbitrario del suministro de agua importa un atentado contra esta garantía, cuando por esta vía se impide o dificulta el ejercicio de la actividad económica del reclamante. En estos casos, sin embargo, no se ha hecho mención directa a la calidad de bien indispensable para la vida.

Pero el verdadero alcance de esta acción de protección debería quedar radicado en los $\mathrm{n}^{\text {os }} 1$ y 8 del art. 19. En la justicia ambiental muchos recurrentes han argumentado su lesión en razón de la afectación de fuentes de agua. Los fallos no siempre han sido alentadores.

Puede también que los tribunales apliquen directamente los tratados internacionales aludidos y, así, se asegure el Derecho al Agua, lo cual no carece de problemas. Primero, el juez ante la decisión de aplicar la norma general contenida en ellos deberá proceder a darle un contenido concreto, debiendo pronunciarse sobre tecnicismos y se enfrentará a normas de gran complejidad. ¿Qué norma sobre la calidad del agua potable usará, la nacional o quizás un criterio de organismos internacionales? Se dirá que debería servirse de las normas 
internas, pero es cierto que debe buscarse la mayor protección de los derechos de las personas, y es que muchas veces recibirá un enunciado carente de un contenido, pues las normas internas no siempre se han dictado y, si existen, no siempre responden a estándares internacionales.

Por otra parte, como en el sistema chileno los derechos de aprovechamiento de aguas pertenecen a los particulares y los servicios sanitarios son proporcionados por empresas privadas, está la posibilidad de que el tribunal aplique el derecho directamente en relaciones entre particulares, surgiendo otra antigua polémica, la del efecto horizontal de los derechos fundamentales. Podría eludirse esta disyuntiva mediante un recurso de inaplicabilidad por inconstitucionalidad (excluyendo, si se acoge, de las normas aplicables al caso aquella de la cual se recurre y radicando en esa sede la discusión), pero es dudoso -y la jurisprudencia parece así demostrarlo- que por este camino se declare la inaplicabilidad de un precepto legal por ser contrario a un Tratado (argumentando que se infringiría por tanto el art. $5^{\circ}$ inciso 2 de la Constitución). ¿Y, entonces, en caso de decidir aplicar el tratado, lo aplicará como norma directamente o solo como principio? ¿Deberá en este caso imponer a los particulares el deber de protección directo de este derecho, o deberá obligar al Estado?

Recordando que hasta ahora el principal obligado es el Estado, en el evento de que el juez usara como guía la Observación $n^{\circ} 15$, podría encontrarse con que no existe norma que lo obligue en el ordenamiento chileno, entonces, ¿podría por este camino imponerse acciones u omisiones a los particulares que no estén contenidas ya en la ley, pero que son más acordes a la concepción internacional del Derecho al Agua?

Algunos caracteres del derecho al agua podemos encontrarlos en la Ley General de Servicios Sanitarios (DFL. $n^{\circ} 382$ de 30 de diciembre de 1988) y en la Ley 18.778 de 2 de febrero de 1989. El art. 33 del primer cuerpo legal dispone que el prestador estará obligado a prestar servicio a quien lo solicite. Mientras que el segundo, consagra dos subsidios, uno al consumo y que le toca pagar a las municipalidades, y otro de inversión, que corresponde a una parte de la inversión en sistemas de agua potable rurales y que debe pagar al Ministerio de Obras Públicas.

Pero las fechas de ambos cuerpos legales son anteriores a la de la Observación, no constituyendo una recepción propiamente tal de su contenido, sino una manifestación concreta de la obligación del Estado de satisfacer el bien común, norma que ya estaba contenida en la Constitución y que es felizmente coincidente con lo que después se entendería como una obligación estatal por el Comité al interpretar el art. 11 del Pacto.

Por cierto, en defecto de lo anterior, queda la posibilidad de acudir al sistema interamericano de protección de los derechos humanos. Un ejemplo concreto y reciente de aplicación del Derecho al Agua lo encontramos en el caso Comunidad indígena Xákmok Kásek versus Paraguay, no siendo, por cierto, el único. 


\section{CONCLUSIONES}

En el presente trabajo se ha podido apreciar algunos de los problemas que presenta el Derecho al Agua en su recepción en el ordenamiento jurídico chileno.

Se observa en el plano del Derecho Internacional de los Derechos Humanos un movimiento consistente, primero, en reconocer el Derecho al Agua como un Derecho Humano, más allá del imperativo moral de que todo ser humano debe tener acceso al agua, dotándolo luego de contenido. Este reconocimiento jurídico positivo, en principio, es recepcionado por nuestra legislación a través de diversos tratados internacionales. Pero considerando los enunciados de las normas de dichos tratados, es discutible que el contenido atribuido por la interpretación hecha por el Comité en la Observación General no 15 sea recibido por el ordenamiento chileno en atención a su naturaleza jurídica. Se corre el riesgo, entonces, de que el derecho se reciba, pero sin contenido.

Mas, aun integrando dicho contenido, surgen problemas que tienen como punto de partida dos consideraciones que a su vez inspiran el régimen general del agua en Chile, a saber: el agua es un bien esencialmente económico y el mercado es el encargado de distribuir $y$ asignar el recurso. Si la Observación nos dice que el agua es esencialmente un bien social y cultural (no solo económico), ¿cómo lo conciliamos con un derecho (real) perpetuo, o con los derechos no consuntivos a favor de hidroeléctricas? Y si el ejercicio no admite más discriminaciones que aquellas que fundadamente exija la necesidad de subsistencia, ¡cómo conciliarlo con un sistema de remates, la libre transacción de derechos y la especulación amparada por el sistema?

Incluso más, ¿dónde encontramos las herramientas institucionales para lograr las prestaciones del Estado (principal obligado) dentro de un sistema esencialmente entregado a los particulares? La introducción de este contenido incompatible, no solo con la letra, sino con el espíritu de la ley, permitiría repreguntarnos, ¿podría plantearse una derogación del Código de Aguas de estimar la inclusión de este derecho y dicho contenido, y que se relaciona con el problema de la jerarquía de estos tratados?

Lo que existe en nuestro país, estimamos, es una elaboración incipiente, atomizada y para nada pormenorizada del contenido ideal del Derecho al Agua inserto en diversos cuerpos legales, confundiéndose en su aplicación con otros derechos. De lo anterior podemos ver un reflejo en la jurisprudencia.

No hay mecanismos amplios para suplir desigualdades (los que existen son restrictivos o condicionados). Por el contrario, su contenido inclusivo, se ve eclipsado por una suma de derechos patrimoniales que perpetúan desigualdades que el Estado se ve sobrepasado en subsanar. Así, en Chile el derecho que hemos analizado, y haciendo un esfuerzo por separarlo conceptual y funcionalmente de otros, se reduciría más bien al Derecho al Agua Potable y a algunos servicios sanitarios. 
Finalmente, el pleno reconocimiento, más que solo un tema de reformas legales, pasa por un giro en la concepción de un sistema añoso, cada vez más difícil de justificar, y sobre todo por una nueva visión del agua, de la convivencia y de la dignidad humana, que es lo que se buscó con el Pacto Internacional de Derechos Económicos, Sociales y Culturales, y a lo que adhirió Chile al suscribirlo. 


\section{REFERENCIAS BIBLIOGRÁFICAS}

Bidart Campos, Germán. Teoría general de los Derechos Humanos. México D.F., México: Universidad Autónoma de México, 1989.

Ferrajoli, Luigi. Derechos y garantías; La ley del más débil. -4a edición-, Madrid, España: Editorial Trotta, 2004.

Nogueira Alcalá, Humberto. Teoría y dogmática de los Derechos Fundamentales. México D.F., México: Universidad Autónoma de México, 2003.

"Aspectos de una Teoría de los Derechos Fundamentales: La Delimitación, Regulación, Garantías y Limitaciones de los Derechos Fundamentales”, en: Ius et Praxis, vol. 11, no 2, pp. 15-64. Talca, Chile: Facultad de Ciencias Jurídicas y Sociales, Universidad de Talca, 2005.

"Los derechos económicos, sociales y culturales como derechos fundamentales efectivos en el constitucionalismo democrático latinoamericano”, en: Estudios constitucionales, vol. 7, n 2, pp. 143-205. Talca, Chile: Centro de Estudios Constitucionales, Universidad de Talca, 2009.

Peña Chacón, Mario. "Derecho Humano al Agua”, en Medio Ambiente \& Derecho: Revista electrónica de derecho ambiental. <En Línea> Grupo de Investigación de Medio Ambiente y Derecho, Universidad de Sevilla, España, No 16, septiembre 2007 [Citado 29 junio 2010]. Disponible en la World Wide Web: <http://huespedes.cica.es/aliens/gimadus/16/08_dere_human_agua.htm>

Peñalver Cabré, Alex. "Aproximación al marco jurídico del derecho humano al agua: una perspectiva desde el derecho interno", en Serie Carta de Derechos Humanos Emergentes: Derecho Humano al acceso al agua potable y al saneamiento. <En Línea> Institut de Drets Humans de Catalunya, Cataluńa, Espańa, No 4, 2008, pp. 8 y ss. [Citado 29 junio 2010]. Disponible en la World Wide Web: <http://www.idhc.org/esp/ documents/Biblio/CDHE_04.pdf>

SÁnchez, Víctor M. "Hacia un derecho humano fundamental al agua en el derecho internacional", en Revista Electrónica de Estudios Internacionales. <En línea>, Asociación Espańola de Profesores de Derecho Internacional y Relaciones Internacionales, Madrid, Espańa, $N^{\circ}$ 16, 2008. [Citado 29 Junio 2010] Disponible en la World Wide Web: <http://www.reei.org/reei\%2016/doc/SANCHEZ_Victora.pdf>

Saura EstapÀ, Jaume. “Agua y derechos humanos: las bases del derecho humano al agua”, en Serie Carta de Derechos Humanos Emergentes: Derecho Humano al acceso al agua potable y al saneamiento. $<$ En Línea> Institut de Drets Humans de Catalunya, Cataluña, Espańa, No 4, 2008, p. 123. [Citado 29 junio 2010]. Disponible en la World Wide Web: <http://www.idhc.org/esp/documents/Biblio/CDHE_04. pdf>

Smets, Henri. Por un derecho efectivo al agua potable. Bogotá, Colombia: Editorial Universidad del Rosario, 2006. 